\title{
CORRECTION
}

\section{Correction to: Diachronic equivalence: an examination of the international news network}

\section{George A. Barnett ${ }^{1} \cdot$ Carlos Algara $^{1}$}

Published online: 18 May 2020

(c) Springer-Verlag GmbH Austria, part of Springer Nature 2020

\section{Correction to:Social Network Analysis and Mining (2019) 9:6 https://doi.org/10.1007/s13278-019-0549-y}

In the original publication funding information was missed to update and it should read as follows.

Funding The research reported in Barnett and Algara was funded in whole by Award \#W911NF-15-1-0502 from the Department of Defense and U.S. Army Research Office/
Army Research Laboratory under the Minerva Research Initiative. The views expressed are those of the authors and should not be attributed to the Department of Defense or the Army Research Office/Army Research Laboratory.

Publisher's Note Springer Nature remains neutral with regard to jurisdictional claims in published maps and institutional affiliations.
The original article can be found online at https://doi.org/10.1007/ s13278-019-0549-y.

George A. Barnett

gabarnett@ucdavis.edu

Carlos Algara

calagara@ucdavis.edu

1 University of California, Davis, Davis, CA, USA 